professionals are increasingly taking decisions and actions which entail often prolonged sufferings by others, frequently without full consideration of the logical consequences, or disregarding them, and without the preparedness to give help in mitigation as and when it is needed. That we conceal even from ourselves the true nature of our actions with the blindfolds of 'absolute duty to preserve life', 'community-care', 'being non-directive, non-judgemental, non-paternalistic', simply adds the extra sin of wilful ignorance.

Lastly, what help, if any, is offered to the NOB who may have to contend with their own feelings of total revulsion from mutilations, e.g. amputations, and therefore with guilt-feelings as well? Particularly if a relationship is ambivalent anyway, these may well outweigh their sympathy or pity-but of course it is not acceptable to admit this.

Mount Pleasant Hospital,

Paula H. Gosling

Frederick Road, Hastings

\section{UP-TO-DATE RECORDS OF LONG-STAY PATIENTS}

DeAr Sir,

We refer to correspondence on this topic (Journal, February, 1980, 136, 203-4; May 1980, 136, 523) and suggest that the main reason for the inadequacy of the case notes of chronic patients is not that useful information is inaccessible but that case notes often omit altogether data which we now regard as essential. This is not surprising since case notes were designed for case-management by doctors, who are mainly interested in the biological aspects of a case. (Witness the poverty of entries in a chronic patient's case file, apart from those recording injury or intercurrent illness). Nurses, too, write notes primarily for their own use and in most hospitals now use a separate Kardex system. We feel that a comprehensive assessment of both assets and disability giving weight to social as well as to biological factors, and the need to plan and monitor chronic patients' care and rehabilitation, require a recording system of a radically different kind in addition to traditional records.

The best system for this purpose is a matter for debate. Assuming that a chronic patient's case is managed strategically, as it were, by a staff group meeting monthly (and considering each patient on the ward at say six-monthly intervals) we agree that the record should contain all the data the group needs for its job, including statements of previous conclusions and recommendations; such data as have been mentioned by Dr Henryk-Gutt and Dr Roger
Morgan. However, there is something to be said for using printed forms on which data are recorded in clearly set out sections. This helps to ensure that important areas are not missed, facilitates the identification of areas which need attention, and if the sections are covered methodically can impart a regular structure to the review meeting itself.

Over the last three years at this hospital five forms have been developed, together with a guide. One form (blue) is for recording basic current information; three rating scales are used for rating deviant and general ward behaviour (pink), work performance (yellow) and OT performance (white); the fifth form (green) is a summary sheet for recording rating scores, the patient's attitude to discharge and work outside the hospital, and the conclusions of the assessment meeting (under the headings: greatest current problems; general goals; actions to be taken). The rating scales are filled in by the staff best placed to observe the patient's behaviour and include clearly written instructions. It is intended that assessment meetings should include an interview with each patient to discuss proposed changes with him and to rate his attitude to discharge and to outside work. At the end of each meeting the forms are returned to the local case-register centre, which sends back to the ward the basic current information and summary sheets as well as an updated print-out of the rating scores from the four latest assessments. These are filed in a prominent place in the notes, permitting staff to check on the actions to be taken.

The system works well on a number of wards and at the Day Hospital. Although there were some problems in implementing the system on a few wards, these have been largely overcome through monthly meetings between staff on long-stay wards and members of the Rehabilitation Committee. Apart from this, we believe that the recording system itself is a useful educational aid for staff working in the field of rehabilitation and social care.

I. G. Prycr

Whitchurch Hospital,

J. N. Hall

Whitchurch, Cardiff CF4 7XB

\section{HLA-ANTIGENS, SCHIZOPHRENIA AND BRAIN ATROPHY}

Dear Sir,

Luchins et al (Journal, March 1980, 136, 243-48)

reported a possible association between HLA-A2, schizophrenia and brain atrophy: this antigen was increased in their black schizophrenic patients' group, and remained increased in a sub-group of patients without evidence of brain atrophy, while 
this difference did not appear in the sub-group of patients with atrophy.

In an earlier study we found an association between HLA-B27 and schizophrenia (Gattaz et al, 1980). In order to investigate the mentioned correlation between the HLA-system and brain atrophy in schizophrenia, we carried out a computed tomographic study in $\mathbf{4 0}$ patients meeting the Feighner (1972) diagnostic criteria for schizophrenia.

Considering the transverse measure of the 3rd ventricle, we subdivided the patients into two subgroups with 3rd ventricle larger and smaller than the median measure $(4.5 \mathrm{~mm})$ respectively. Comparing the HLA incidence between these sub-groups, we failed to find any significant difference with HLAB27 or with HLA-A2. This latter appeared in 47.6 per cent of the patients with larger 3rd ventricle and in 26.3 per cent of patients with smaller 3rd ventricle (in a control group of 472 healthy individuals HLA-A2 appeared in 47.0 per cent). Although this difference was not significant $\left(\%^{2}=1.9 ; \mathrm{P}=0.16\right)$, it pointed in the opposite direction to the finding of Luchins et al: HLA-A2 was decreased in the sub-group of patients with 3rd ventricle smaller than the median; i.e. without brain atrophy.

The difference between the findings of Luchins et al and ours could have several explanations. As the former stressed, differences in diagnostic systems and biological differences among schizophrenic patients must be considered. Concerning HLA typing, we would add some more possible sources of bias:

(1) The use of different serological procedures, or even the use of different anti-sera, as it has been shown that there is sometimes no anti- sera specificity for a particular antigen.

(2) Ethnic heterogeneity between the compared groups, as HLA incidence differs among different races (Svejgaard et al, 1975).

(3) Due to the great polymorphism of the HLAsystem, studies on small samples run the risk of picking up false associations (type-I error).

Concluding, we do agree with Luchins and collaborators when they postulate the necessity of using different biological parameters in the selection of more homogeneous groups of schizophrenics, but it seems unlikely that CT findings could serve this purpose, as although a number of researchers have found an increased occurrence of brain atrophy among schizophrenics, these data are still not universally agreed.

WAgner F. Gattaz
Siegrried Kasper
Helmut Beckmann
Zentralinstitut für Seelische Gesundheit,
6800 Mannheim, I 5
West Germany

\section{References}

Feighner, J. P., Robins, E., Guze, S., Woodruft, R. A., WinokUR, G. \& MUNOz, R. (1972) Diagnostic criteria for use in psychiatric research. Archives of General Psychiatry, 26, 57-63.

Gattaz, W. F., Ewald, R. W. \& Beckmann, H. (1980) The HLA system and schizophrenia: a study in a German population. Archiv für Psychiatrie und Nervenkrankheilen, 228, 205-11.

Sjejgaard, A., Platz, P., Ryder, L. P., Staub-Nielsen, L. \& Thomsen, M. (1975) HLA and disease associations: a survey. Transplantation Review, 22, 2-43. 